\title{
Erratum to: Emotional Variability in Mother-Adolescent Conflict Interactions and Internalizing Problems of Mothers and Adolescents: Dyadic and Individual Processes
}

\author{
Daniëlle Van der Giessen • Tom Hollenstein • \\ William W. Hale III • Hans M. Koot • Wim Meeus • \\ Susan Branje
}

Published online: 28 August 2014

(C) Springer Science+Business Media New York 2014

Erratum to: Journal of Abnormal Child Psychology

DOI 10.1007/s10802-014-9910-9

In the original version of this article, the name of one coauthor, W. Meeus, was erroneously listed as affiliated with the University of Amsterdam, The Netherlands. W. Meeus is affiliated with Utrecht University and Tilburg University in the Netherlands. A correct list of all author affiliations is given here.

The online version of the original article can be found at http://dx.doi.org/ 10.1007/s10802-014-9910-9.

D. Van der Giessen $(\bowtie)$

Department of Child Development and Education, Research Priority

Area Yield, University of Amsterdam, P.O. Box 94208, 1090

GE Amsterdam, The Netherlands

e-mail: D.vandergiessen@uva.nl

T. Hollenstein

Queen's University, Kingston, Canada

W. W. Hale III $\cdot$ W. Meeus $\cdot$ S. Branje

Utrecht University, Utrecht, The Netherlands

H. M. Koot

VU University, Amsterdam, The Netherlands

W. Meeus

Tilburg University, Tilburg, The Netherlands 